\title{
Word Choice and Symbolic Language: A Case Study of Persian Translations of THE SCARLET LETTER
}

\author{
Hossein Vahid Dastjerdi, Associate Professor of TEFL \\ English Department, University of Isfahan, Isfahan, Iran \\ E-mail: h_vahid@yahoo.com \\ Elahe Madah Shoorche \\ M.A. of Translation Studies, University of Shaikhbahai, Iran \\ E-mail: appel.1234@yahoo.com
}

Received: March 28, $2011 \quad$ Accepted: April 28, $2011 \quad$ doi:10.5539/ijel.v1n2p186

\begin{abstract}
The purpose of the present study was to investigate the stylistic devices in the two Persian translations of the novel The Scarlet Letter, with special focus on symbol and word choice. The participants of the study were 24 M.A students of translation studies. The data were collected through a researcher-developed questionnaire. The findings indicated that not only universal symbols are translatable, but also culture-specific symbols can be translated from one language into another, with some trivial nuance of meaning lost. Also, the findings of the study suggested that for the target readers' better understanding, translators should give footnote for culture-specific symbols. As to the word choice (i.e. the sense of archaic words), the translators have not preserved this feature as precisely as it appears in the original novel; instead, they have used old Persian syntactic structures which compensate for the loss of the sense of archaic words.
\end{abstract}

Keywords: Stylistic device, Symbol, Word choice, Relevance Theory, Translation

\section{Introduction}

So far, a number of studies have been done by both scholars and students concerning the topic of the present research. Most of the studies related to the topic of this research have been done in the field of strategies and procedures for translating symbols. Michelson (2005:176) considers a figure of speech "an image transferred by something that stands for or represents something else, like flag for country, or autumn for maturity." Symbols can represent ideas embodied in the image without stating them. Symbols can be subject to a diversity of connotations; therefore, both the poet and the reader must exercise sensible discretion to avoid misinterpretation. (Michelson, 2005:176)

Yusefi Gavarti (2007) in a cross-cultural study investigated the adopted strategies for the translation of birds' symbolic expressions in Attar's The Conference of the Birds. In this study, efforts were in fact made to see to what extent the true sense and image of the original text, i.e. symbolic expressions were imported from Persian into English. The findings of the study suggested that due to the fact that symbolic terms are more cultural-bound than universal, none of the translators could successfully import the intended message of the original text. It was also revealed that literal translation turned out to be the most frequent strategy for translating symbols.

In another study Ordudari (2008: 1), argued that translation suffers from many limitations, one of which is the difficulty of translating symbols meaningfully in another language. In his paper, he analyzed how symbols have been dealt with in the two languages: Persian and English. The results of his study showed that symbols are deeply rooted in the source language culture; consequently, translators should exercise care in handling such cultural items. He found that among procedures for translating symbols effectively from Persian to English omission is the most frequently employed one.

Talebinejad (2008) in a study selected the play "Death of a Salesman" by Arthur Miller for analysis in terms of its adaptability for translation across cultures. The purpose was to see if in literary works localization can be achieved through distribution. The model for analysis was adapted from Pym (2004), along with the principles of 
"The Relevance Theory" and the Skopos theory. The analysis showed that from a cultural point of view the message is not moved through the text when adapted in translation into Persian.

The results of the study by Jamshid (2007) in a comparative study of implicit meaning in translation of poetry "Robaiyat of Omar Khayyam" in Persian and English indicated that implicit meaning maybe problematic in translation of poetry and also that implicit meaning is not completely translatable from Persian to English.

Although these researchers have paid attention to symbols in translation, they consider the strategies and procedures for translating symbols from Persian to English, none of them consider the connotation and implicit meaning of symbols in depth from English to Persian. As evidence shows, there is still ambiguity in this area. So, more studies need to be done in this area for the ambiguities to be removed. Hence, this study aims to somehow remove the ambiguities and contribute to this area of research.

\section{Aims and Scope of the Study}

Translation suffers from many limitations, one of which is the difficulty of translating symbols meaningfully in another language. The present study, aimed to see how symbols have been dealt with in the two languages: English and Persian. Actually, the aim of the present study was to consider the translation of stylistic elements in a work of literature. For this purpose, a literary work named The Scarlet Letter and two Persian renderings of it were investigated. Some of the most important stylistic elements which were found in this literary work are: Figurative language (metaphor, simile, irony, symbol, imagery...), Word choice (diction), Syntax (sentence structure), Charactonym and Motif.

The scope of this research was restricted to investigating symbol and word choice (diction) as a case study in The Scarlet Letter.

As far as universal symbols are considered, they don't pose any challenge or problem for the translator because they convey the same meaning and emotion in different cultures and languages. But the problem arises when these symbols are culture-specific. They are symbols which have different connotations and meanings in different cultures and in some cultures and languages they may be absent.

The other point which was investigated in this study was word choice or diction. Authors writing their texts consider not only a word's denotation, but also its connotation. As an example, Hawthrone (1850) used lots of archaic words in The Scarlet Letter to convey the historical setting of the novel. In this study, this aspect of the novel was investigated to see if translators have been successful in conveying it to target readers or not. So, the study tried to find answers to the following questions:

1. To what extent have the true sense and image of English symbols in The Scarlet Letter been transferred to Persian?

2. To what extent have the translators preserved word choice (the sense of archaic words) and the historical setting of the original text in their Persian renderings?

\section{Methodology}

\subsection{Participants}

Twenty four M.A students of translation studies answered the questionnaire which was designed by the researchers for the present study. The logic behind this selection was the relative familiarity of the participants with some of the theories of translation as well as participants' ability to evaluate a translation based on the criteria presented to them. The participants had passed courses in translation such as translation theories, advanced evaluation of translation, critical review of the translated works, etc. Most of the participants had long years of experience in translation.

\subsection{Materials}

To find appropriate answers to the research questions and in order to tackle one of the most controversial issues in accomplishing the task of translating The Scarlet Letter's symbols and word choice into Persian in a precise manner, the following materials were investigated:

\subsubsection{The Scarlet Letter (Hawthorne 1850)}

\subsubsection{Persian translations of The Scarlet Letter}

Two different Persian translations were selected: translations by Simin Daneshvar (1990), and Shohreh Zahedi (1995). The rationale behind selecting this novel was the culture-specific nature of the text and inclusion of symbols and archaic words that cause dramatic problems for translators in rendering concepts and linguistic 
items into Persian in a way that the final product would be a text, irrelevant to the Persian audience and, in relevance theoretic terms, needs maximum effort to process.

\subsubsection{Dictionaries}

1- Oxford advanced learner's dictionary, 6th edition (2001).

2- Haghshenas, A.M. (2003). Millennium English to Persian Dictionary.

\subsubsection{Questionnaire}

In order to evaluate the relevance degree of the Persian translations of the symbols and archaic words of The Scarlet Letter, a questionnaire was designed and developed by the researchers. The questionnaire was composed of four parts: An introduction including explanations and instructions on how the text should be rated; the selected pieces of the original text; two Persian translations of the text; and a table for recording the rates.

After the introduction, first the selected symbol and its connotations in the original novel were presented and then an extract of the novel which contained the symbol followed by its two Persian translations were used. Finally, the rating table (Likert scale) was used for evaluation by the participants. For the archaic words, an extract abounding in archaic words, followed by its two Persian translations with a rating table was used. The appropriate statistics for the present study were frequency, percentile, and mean.

\subsection{Procedures}

First, symbols and the instances of archaic words in the original English text were identified. Second, Persian correspondences for these items were identified in the two translations. Third, the implicit meaning and connotation of each symbol were presented. Fourth, the extent to which translators had been successful in a) transferring the true sense and image of English symbols in The Scarlet Letter to Persian, and b) preserving word choice (the sense of archaic words) and historical setting of the novel in their Persian translations, were discussed. Fifth, the researcher-developed questionnaire was given to M.A students of translation. Based on the answers of the participants, the researchers drew some conclusions.

\section{Data Analysis and Discussion}

\subsection{The data and discussion}

As was mentioned earlier, in this study stylistic devices were under investigation. The scope of the study was restricted to "symbol" and "word choice"; therefore, the results obtained from the analysis of the data, which were gathered from the questionnaire for these two parts, are presented below respectively.

\subsubsection{The data on symbols and its discussion}

To accomplish the goals of this study, the researcher-developed questionnaire was given to participants. The questionnaire contained three questions regarding symbols. The analysis of the answers to these questions is presented below:

In answer to the first question of the questionnaire (i.e., To what extent the translators could receive the intended message of the original writer through the translation?), table 4.1 shows that 42.9 percent of participants rated "very much" and 0.6 percent rated "not at all".

\section{Insert Table 4.1 and Chart 4.1 Here}

Actually, according to table 4.1.1 below, the mean of the scores for the item "very much" is 3.97 which, based on Likert Scale (out of 5), reveals a higher degree of relevance than other items rated by the participants.

\section{Insert Table 4.1.1 Here}

As far as the second question of the questionnaire (i.e., To what extent have the required motives for true communication been preserved in translation?) is concerned, based on table 4.2, 44 percent of translators rated "very much" and 1.2 percent rated "not at all".

\section{Insert Table 4.2 and Chart 4.2 Here}

According to table 4.2.2 below, the mean of the scores is 3.69 which based on Likert Scale (out of 5) indicates that from the point of view of the participants of this study the item "very much" has the highest frequency and is most relevant.

\section{Insert Table 4.2.2 Here}


Considering the third question of the questionnaire (i.e. To what extent have the selected symbols the same connotations and meanings in translation as in the original text?), as it is illustrated in table 4.3, the item "very much" is selected by 34.5 percent of translators and "not at all" by 5.4 percent.

\section{Insert Table 4.3 and Chart 4.3 Here}

Table 4.3.3. below shows that the mean of the scores is 3.64, which according to Likert Scale indicates the fact that the participants of this study selected the item "very much" as the most relevant one.

\section{Insert Table 4.3.3 Here}

Therefore, in all cases, the results were indicative of the fact that from the point of view of the raters, translators have succeeded to a great extent (the mean scores for questions 1, 2, and 3 were 3.97, 3.69, and 3.64 respectively) to transfer the true sense and image of English symbols to Persian.

4.1.2 The data on Word Choice (the sense of archaic words) and its discussion

The analysis of the data obtained from questionnaire is presented in tables below.

As far as the first question of the questionnaire (i.e., To what extent could the translators receive the intended message of the original writer through the translation?) is concerned, according to table 4.4, 62.5 percent of participants rated "very much" and none of the participants chose "not at all".

\section{Insert Table 4.4 and Chart 4.4 Here}

As table 4.4.4 below, shows the mean of the scores is 3.75 which according to Likert Scale is indicative of the fact that the participant of this study considered the item "very much" more relevant.

\section{Insert Table 4.4.4 Here}

In answer to the second question of the questionnaire (i.e., To what extent have the required motives for true communication been preserved in translation?), based on table 4.5, 58.3 percent of translators rated "very much" and the item "not at all" was not selected by any of the raters.

\section{Insert Table 4.5 and Chart 4.5 Here}

Actually, according to table 4.5.5 below, the mean of the scores is 3.58 which based on Likert Scale indicates that from the point of view of the participants of this study the item "very much" is the most relevant.

\section{Insert Table 4.5.5 Here}

Considering the third question of the questionnaire (i.e., To what extent have the translators -Daneshvar and Zahedi- preserved word choice (the sense of archaic words) and historical setting of the original novel in their translations?), as it is illustrated in table 4.6 , the item "to some extent" is selected by 50 percent of participants and items "not at all" and "completely" were not selected.

\section{Insert Table 4.6 and Chart 4.6 Here}

Table 4.6.6 below shows that the mean of the scores is 3.08 which, according to Likert Scale, indicates the fact that the participants of this study selected the item "to some extent" as the most relevant one.

\section{Insert Table 4.6.6 Here}

Therefore, in all cases, the results were indicative of the fact that -from the point of view of the raters- translators have to a great extent (the mean scores for questions 1, 2, and 3 were 3.75, 3.58, and 3.08 respectively) preserved the sense of archaic words and historical setting of the original in their Persian translation renderings. Some examples are as follows:

1). "I charge thee to speak out the name of thy fellow-sinner and fellow-sufferer! Be not silent from any mistaken pity and tenderness for him." (Hawthorne, 1850: 61)

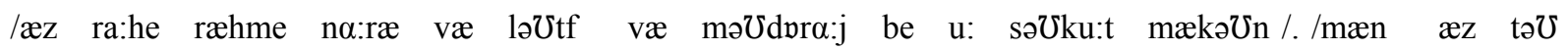

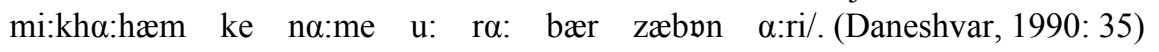

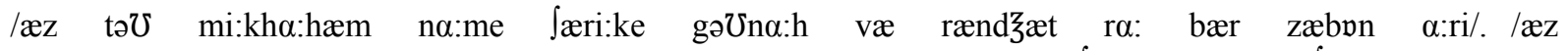

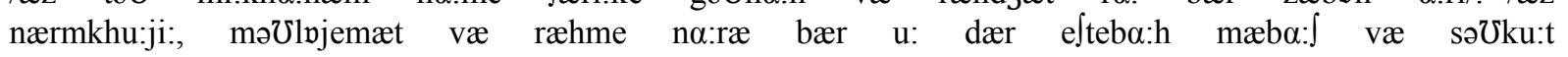
mækəひn /. (Zahedi, 1995:25)

2). "Wouldst thou have me to believe, $O$ wise and pious friend, that a false show can be better- can be more for God's glory, or man's welfare- than God's own truth?” (Hawthorne, 1850: 118-119) 


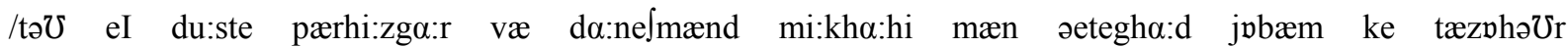

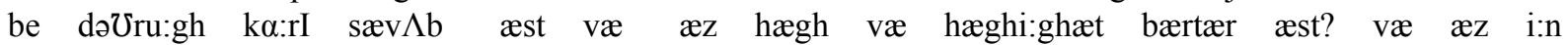

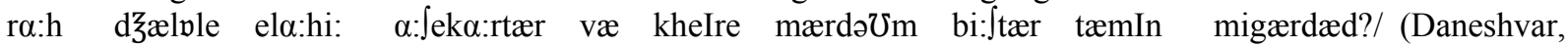
1990: 104)

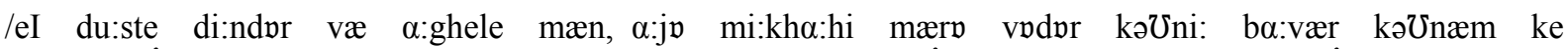

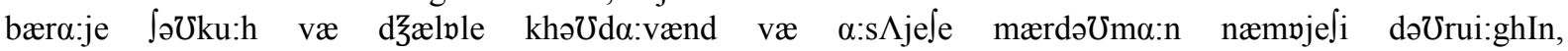

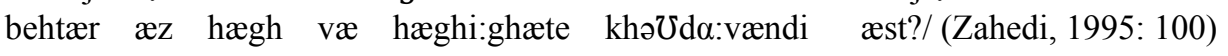

\section{Results and conclusion}

In this study the researchers sought to investigate stylistic devices in a literary work (The Scarlet Letter), the scope of which was restricted to "symbol" and "word choice". From the findings of this study, it can be concluded that not only universal symbols or archetypes are translatable from one language into another, but also culture-specific symbols can to a great extent (the mean scores for questions 1, 2, and 3 were 3.97, 3.69, and 3.64 respectively) be transferred across languages successfully. Only some nuances of meaning and connotative meanings may be lost which can be ignored because the main concept of culture-specific symbols are transferred to the target language and most of the symbols arouse a common sense among different nations. This is because people from diverse cultures can communicate with each other and can understand the literature of one another. If it weren't so, then communication between nations would cease. As an example, in The Scarlet Letter, the scarlet letter "A" was a culture-specific symbol for the Puritans of its time (1850) but it is translated into

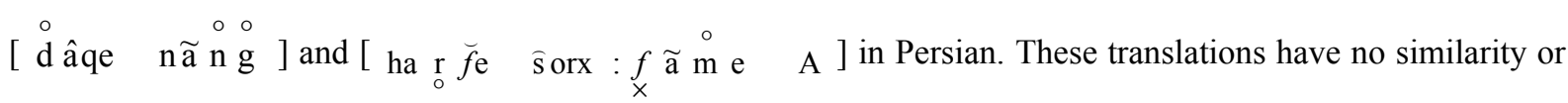
connotation with the scarlet letter "A", because the letter "A" in the original novel stands for both adultery and angel. It has nothing to do with $\left[\begin{array}{lllllll}\text { ha } & \underset{0}{\mathrm{r}} \breve{f} \mathrm{e} & \widehat{\mathrm{s}} \text { orx } & : \underset{\times}{f} \underset{\times}{\widetilde{a}} \stackrel{\circ}{\mathrm{m}} \mathrm{e} & \mathrm{A}\end{array}\right]$ in Persian. In spite of this fact, the Persian reader can understand and comprehend the story completely. It was suggested by the participants of the study that in such cases, for the target readers' better understanding, translators should give footnotes for the culture-specific symbols.

As for word choice, the researchers investigated the archaic words of the novel The Scarlet Letter. In the original novel the writer used archaic words in direct speech of the novel's characters. These archaic words were mostly pronouns such as thou, thee, thy and archaic verbs such as dost, didst, wilt, wouldst, canst, hath, meetest, tellest, hearest, feelest, thinkest, seest, deniest, etc. But none of the translators have preserved word choice (the sense of archaic words) as precisely as it appears in the original novel. Instead, in some instances they have used old Persian syntactic structures which compensate for the loss of the sense of archaic words.

In other words, from the point of view of the participants of this study, word choice (the sense of archaic words) and historical setting of the original novel were to a great extent (the mean for the items related to questions 1, 2, and 3 were $3.75,3.58$, and 3.08 respectively) preserved in the target text.

\section{References}

Daneshvar, S. (1990). Daaghe Nang. Kharazmi Publications: Tehran.

Haghshenas, A. M. (2003). Millennium English to Persian dictionary. Tehran: Farhang-e- Pajoohesh.

Hawthorne, N. (1850). The Scarlet Letter. York press.

Jamshid, S. (2007). A Comparative Study of Implicit Meaning in Translation of Poetry: Rubaiyat of Omar Khayyam in Persian and English. Unpublished M. A. Thesis.

Michelson, R. (2005). Dictionary of Rhetoric. New Delhi: IVY Publishing House.

Ordudari, M. (2008). How to Face Challenging Symbols: Translating Symbols from Persian to English. Translation Journal, 12/4, 1.

Oxford advanced learner's dictionary, $6^{\text {th }}$ edition. (2001). Oxford: Oxford University Press. 
Pym, A. (2004). The moving texts: localization, translation, and distribution. Amsterdam: John Benjamins Publishing Company.

Talebinezhad, M.R. (2008). Translation in Literary Discourse: Distribution Approached from Localization/Localization Approached from Distribution in Literary Texts. Journal of Language and Translation, 9/2, 95-116.

Yusefi Gavarti, N. (2007). A Cross-cultural Study of the Adopted Strategies for the Translation of Birds' Symbolic Expressions in Attar's The Conference of the Birds: How to remove barriers in translation of symbolism. Unpublished M. A. Thesis.

Zahedi, Sh. (1995). Daaghe Nang. Kooshesh Publications: Tehran.

Table 4.1 The frequency and percentile of answers for question 1

\begin{tabular}{|l|c|c|c|c|}
\hline & Frequency & Percent & Valid Percent & $\begin{array}{l}\text { Cumulative } \\
\text { Percent }\end{array}$ \\
\hline not at all & 1 & .6 & .6 & .6 \\
a little & 12 & 7.1 & 7.1 & 7.7 \\
to some extent & 30 & 17.9 & 17.9 & 25.6 \\
very much & 72 & 42.9 & 42.9 & 68.5 \\
Completely & 53 & 31.5 & 31.5 & 100.0 \\
Total & 168 & 100.0 & 100.0 & \\
\hline
\end{tabular}

Table 4.1.1 The mean of the scores assigned to question 1

\begin{tabular}{|c|c|c|c|c|}
\hline & Mean & $\mathrm{N}$ & Variance & $\begin{array}{l}\text { Std. } \\
\text { Deviation }\end{array}$ \\
\hline Question 1 & 3.97 & 168 & .838 & .9154 \\
\hline
\end{tabular}

Table 4.2 The frequency and percentile of answers for question 2

\begin{tabular}{|l|c|c|c|l|}
\hline & Frequency & Percent & Valid Percent & $\begin{array}{l}\text { Cumulative } \\
\text { Percent }\end{array}$ \\
\hline not at all & 2 & 1.2 & 1.2 & 1.2 \\
a little & 12 & 7.1 & 7.1 & 8.3 \\
to some extent & 51 & 30.4 & 30.4 & 38.7 \\
very much & 74 & 44.0 & 44.0 & 82.7 \\
Completely & 29 & 17.3 & 17.3 & 100.0 \\
Total & 168 & 100.0 & 100.0 & \\
\hline
\end{tabular}

Table 4.2.2 The mean of the scores assigned to question 2

\begin{tabular}{|l|c|l|l|l|}
\hline & Mean & $\mathrm{N}$ & Variance & $\begin{array}{l}\text { Std. } \\
\text { Deviation }\end{array}$ \\
\hline Question 2 & 3.69 & 168 & .778 & .8820 \\
\hline
\end{tabular}


Table 4.3 The frequency and percentile of answers for question 3

\begin{tabular}{|l|c|c|c|c|}
\hline & Frequency & Percent & Valid Percent & $\begin{array}{l}\text { Cumulative } \\
\text { Percent }\end{array}$ \\
\hline not at all & 9 & 5.4 & 5.4 & 5.4 \\
a little & 19 & 11.3 & 11.3 & 16.7 \\
to some extent & 38 & 22.6 & 22.6 & 39.3 \\
very much & 58 & 34.5 & 34.5 & 73.8 \\
Completely & 44 & 26.2 & 26.2 & 100.0 \\
Total & 168 & 100.0 & 100.0 & \\
\hline
\end{tabular}

Table 4.3.3 The mean of the scores assigned to question 3

\begin{tabular}{|c|c|c|c|c|}
\hline & Mean & $\mathrm{N}$ & Variance & $\begin{array}{c}\text { Std. } \\
\text { Deviation }\end{array}$ \\
\hline Question 3 & 3.64 & 168 & 1.307 & 1.1432 \\
\hline
\end{tabular}

Table 4.4 The frequency and percentile of answers for question 1

\begin{tabular}{|l|c|c|c|c|}
\hline & Frequency & Percent & Valid Percent & $\begin{array}{l}\text { Cumulative } \\
\text { Percent }\end{array}$ \\
\hline not at all & 0 & 0 & 0 & 0 \\
a little & 3 & 12.5 & 12.5 & 12.5 \\
to some extent & 3 & 12.5 & 12.5 & 25.0 \\
very much & 15 & 62.5 & 62.5 & 87.5 \\
Completely & 3 & 12.5 & 12.5 & 100.0 \\
Total & 24 & 100.0 & 100.0 & \\
\hline
\end{tabular}

Table 4.4.4 The mean of the scores assigned to question 1

\begin{tabular}{|l|l|l|l|l|}
\hline & Mean & $\mathrm{N}$ & Variance & $\begin{array}{l}\text { Std. } \\
\text { Deviation }\end{array}$ \\
\hline Question 1 & 3.75 & 24 & .717 & .8467 \\
\hline
\end{tabular}

Table 4.5 The frequency and percentile of answers for question 2

\begin{tabular}{|l|c|c|c|c|}
\hline & Frequency & Percent & Valid Percent & $\begin{array}{l}\text { Cumulative } \\
\text { Percent }\end{array}$ \\
\hline not at all & 0 & 0 & 0 & 0 \\
a little & 4 & 16.7 & 16.7 & 16.7 \\
to some extent & 4 & 16.7 & 16.7 & 33.3 \\
very much & 14 & 58.3 & 58.3 & 91.7 \\
Completely & 2 & 8.3 & 8.3 & 100.0 \\
Total & 24 & 100.0 & 100.0 & \\
\hline
\end{tabular}

Table 4.5.5 The mean of the scores assigned to question 2

\begin{tabular}{|c|c|c|c|c|}
\hline & Mean & $\mathrm{N}$ & Variance & $\begin{array}{l}\text { Std. } \\
\text { Deviation }\end{array}$ \\
\hline Question 2 & 3.58 & 24 & .775 & .8803 \\
\hline
\end{tabular}


Table 4.6 The frequency and percentile of answers for question 3

\begin{tabular}{|l|c|c|c|c|}
\hline & Frequency & Percent & Valid Percent & $\begin{array}{l}\text { Cumulative } \\
\text { Percent }\end{array}$ \\
\hline not at all & 0 & 0 & 0 & 0 \\
a little & 5 & 20.8 & 20.8 & 20.8 \\
to some extent & 12 & 50.0 & 50.0 & 70.8 \\
very much & 7 & 29.2 & 29.2 & 100.0 \\
Completely & 0 & 0 & 0 & \\
Total & 24 & 100.0 & 100.0 & \\
\hline
\end{tabular}

Table 4.6.6 The mean of the scores assigned to question 3

\begin{tabular}{|c|c|c|c|c|}
\hline & Mean & $\mathrm{N}$ & Variance & $\begin{array}{l}\text { Std. } \\
\text { Deviation }\end{array}$ \\
\hline Question 3 & 3.08 & 24 & .514 & .7169 \\
\hline
\end{tabular}

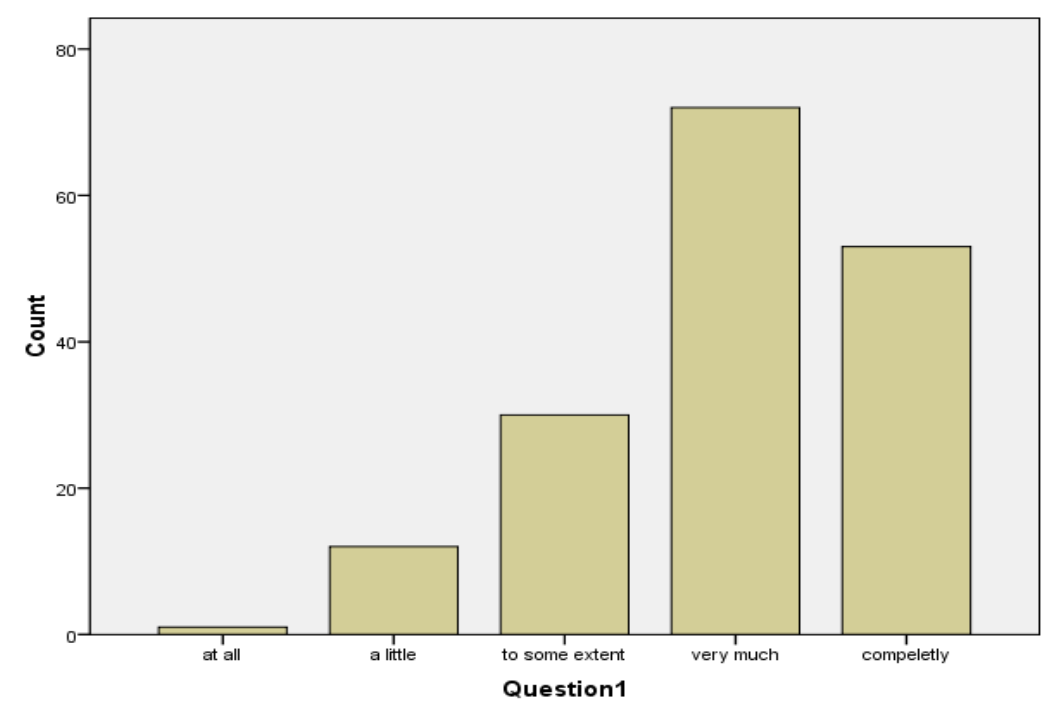

Chart 4.1 Frequency data for question 1

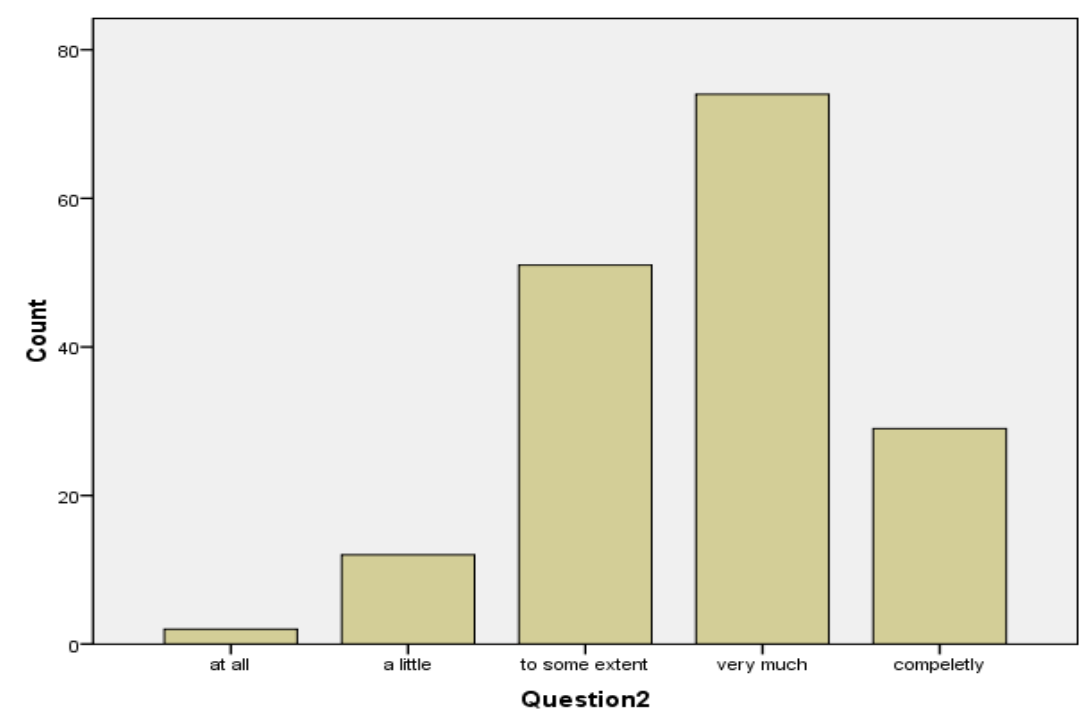

Chart 4.2 Frequency data for question 2 


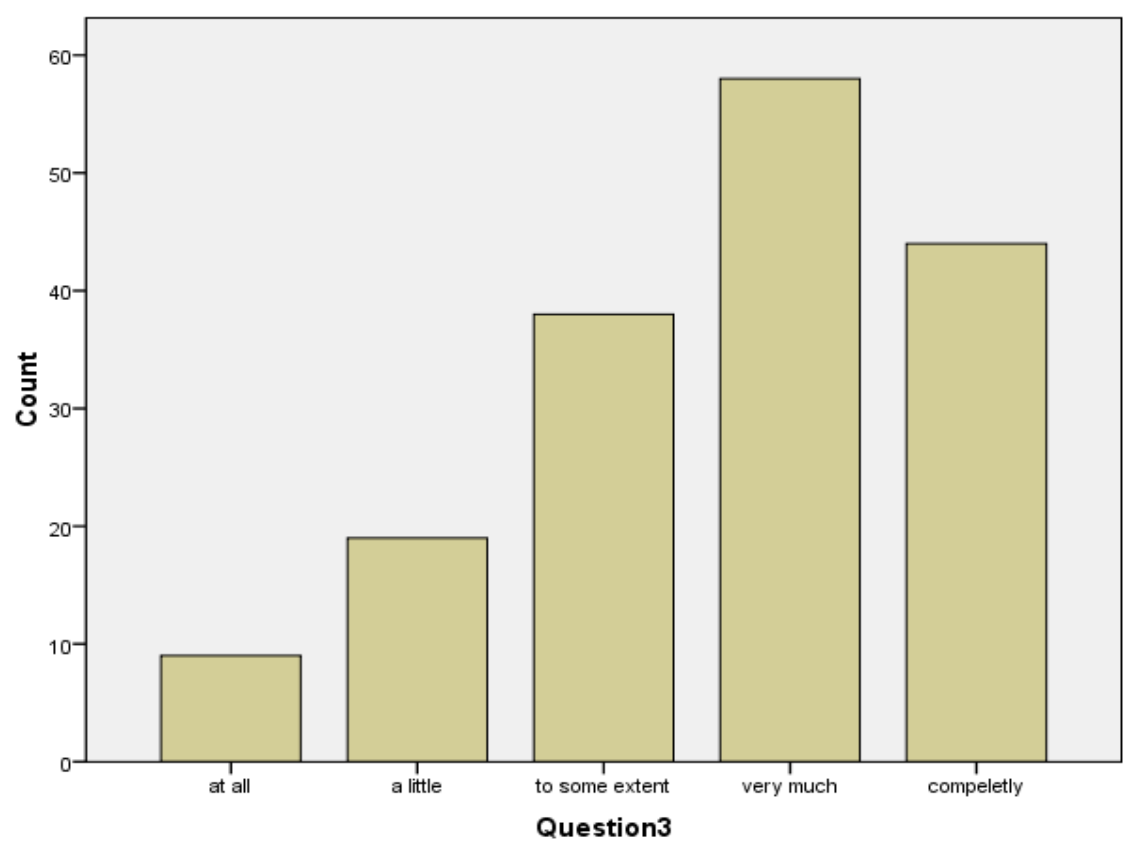

Chart 4.3 Frequency data for question 3

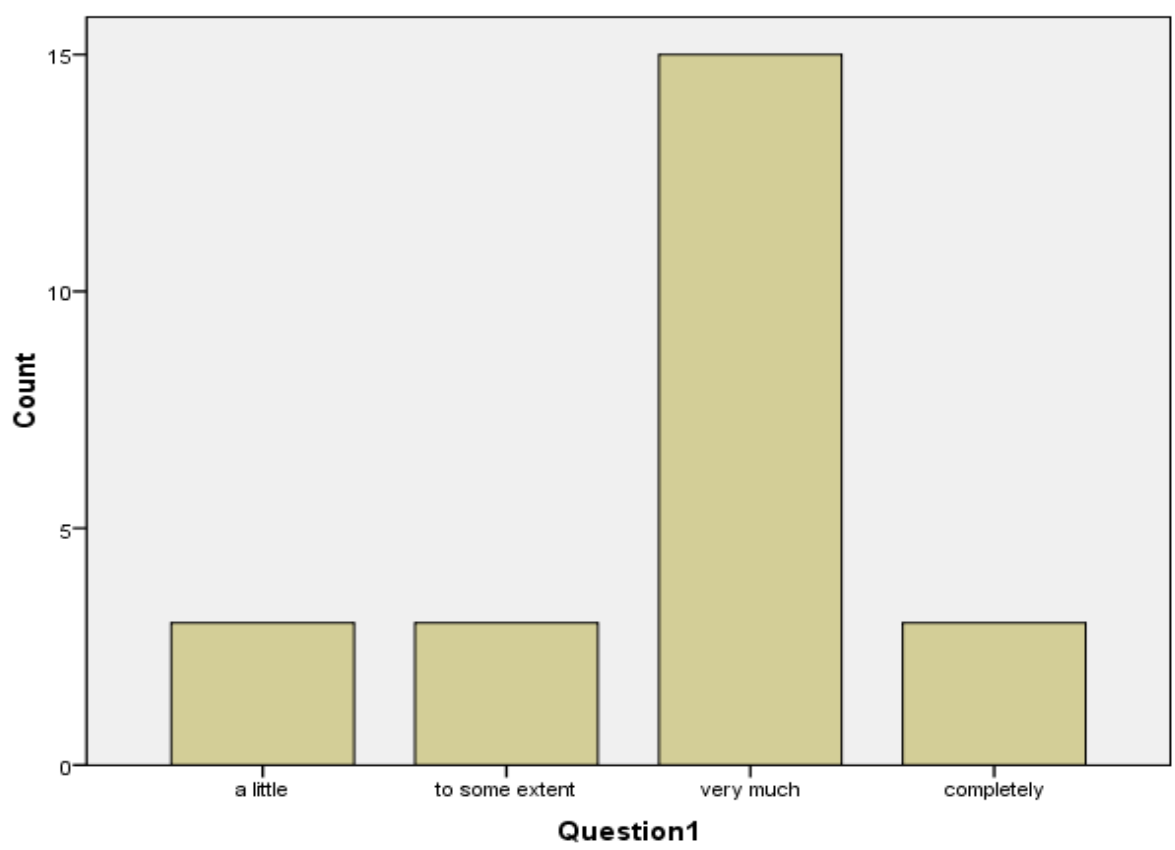

Chart 4.4 Frequency data for question 1 


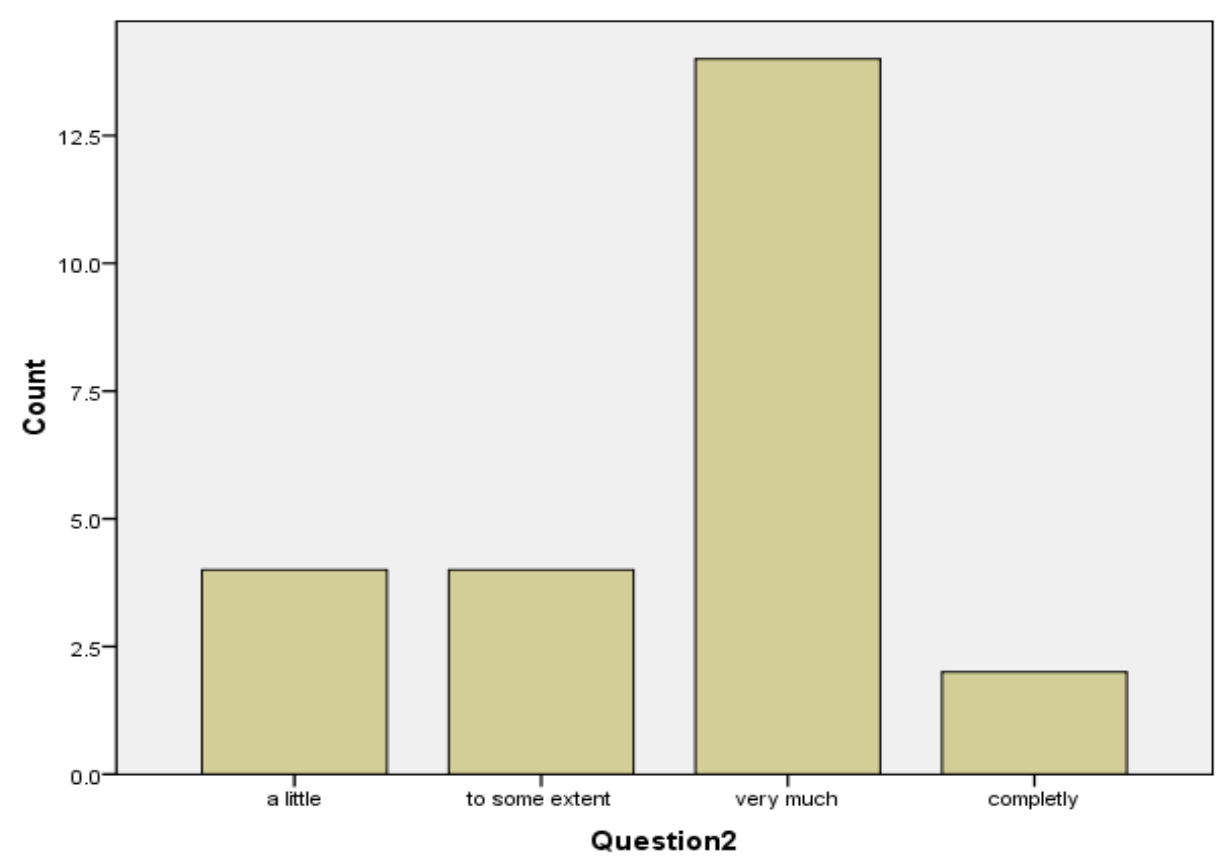

Chart 4.5 Frequency data for question 2

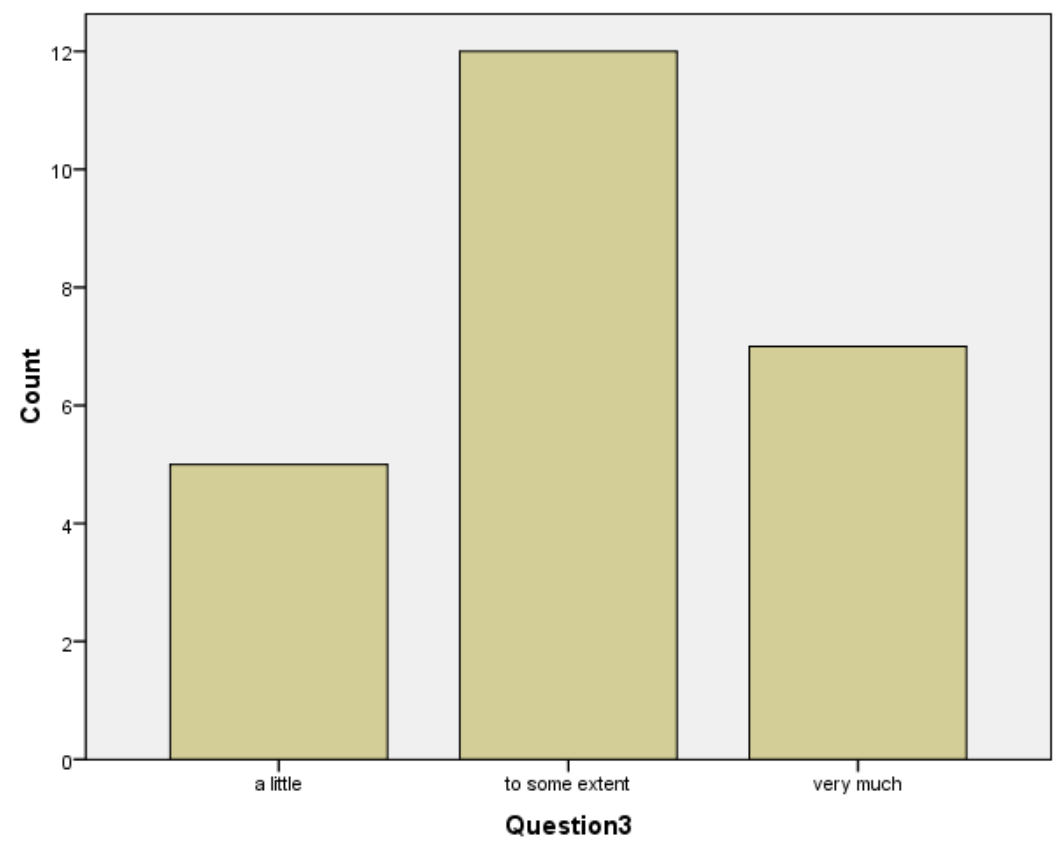

Chart 4.6 Frequency data for question 3 